\section{Prevalence of Autism/ASD in the Capital City of Oslo, Norway}

\author{
Kamil ÖZERK' ${ }^{1}$
}

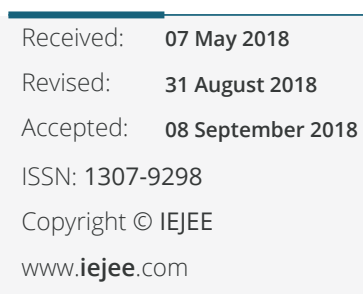

DOI: 10.26822/iejee.2018143957

\begin{abstract}
The prevalence of autism/autism spectrum disorder (ASD) has been increasing across the world. Previous studies in Norway reported, that the prevalence rate for 0-10-year-old children is 1 in 166, and in the case of 11-year-old children it is 1 in 125 . Moreover, another nationwide study discovered that 1 in 192 males and 1 in 695 females between the ages of 1-16 years had autism in Norway in the year 2016. This study is underpinned by the data from the National Patient Registry (NPR) for registered incidences of autism/ASD (ICD-10: F84.0 Childhood autism and F84.5 Asperger syndrome). The results show that the prevalence rates of autism/ASD in the capital city of Oslo increased from 2012 to 2016 and the number of children with autism/ASD doubled during this period. Furthermore, in 2016 the results revealed that that 1 in 349 males and 1 in 1594 females between the ages of 1-5 years old had Autism/ASD. Similarly, among the age group of 6-16 years, 1 among 157 males and 1 among 544 females had autism/ASD in the capital city of Oslo in 2016. These findings suggest a 'school-age-effect' in the increase of prevalence rates among the school-age children compared to the preschool-age children. In the following study, the results are presented and discussed along with some suggestions for the educational and healthcare authorities.
\end{abstract}

Keywords: Prevalence, autism, autism spectrum disorder (ASD), school-age-effect, Oslo, Norway

\section{Introduction}

Prevalence studies of autism/autism spectrum disorder (ASD) are important resources for the databased planning of services by the educational and healthcare authorities. The number of children with Autism/ASD has increased across the world, during the last decade (Fombonne, 2005; Elsabbagh et al., 2012; Özerk, 2016). However, the rise in the prevalence rates has raised several concerns regarding the lack of qualified staff in the kindergartens and schools for treatment, training and teaching, along with the weak awareness among the decision makers about the special needs of these children.

A particular concern was also mentioned about the necessity of planning and the implementation of evidence-based programs for children with autism/ASD (Odom, Boyd, Hall, \& Hume, 2010; Isaksen, 2010; Hart \& Malian, 2013; Eikeseth, 2014; Wong et al., 2015; Lauderdale-Littin \& Brennan, 2018). Furthermore, the rise in the prevalence rates has led to several assumptions associated with its increase and variations. The following factors were extensively discussed in several studies:

a) Changes in Diagnostic and Statistical Manual of Mental Disorders (DSM) in the US and in the International Classification of Diseases (ICD) over the years (Baird et. al., 2006; Bishop; Whitehouse, Watt, \& Knot, 2008; Howlin, 2008; Hansen, Schendel, \& Parner, 2015; Cardinal \& Griffiths, 2016; Cardinal \& Fraumeni-McBride, 2017).

b) Increased competency, better instruments, improved recognition along with detection, increased awareness among educational and clinical professionals have also been recognized as some of the factors responsible for the rise in its prevalence (Wing \& Potter 2002; Williams, Higgins, \& Brayne, 2006; Baron-Cohen et al. 2009; Elsabbagh et. al., 2012). Furthermore, Geographic location, availability of suitable funding and better professional services are also mentioned in these studies.

c) In a recent study, Özerk and Cardinal (2018 in press) recognized the 'school-age effect' as an important factor for the increase of prevalence rates of Autism/ASD among the school-age children compared to the preschool age. There are several studies, which support the 'school-age effect'-hypothesis (Green, McGinnity, Meltzer, Ford, \& Goodman, 2004; Tebruegge, Nandini, \& Ritchie, 2004; Chakrabarti \& Fombonne, 2005; Parner, Schendel, \& Thorsen, 2008; Baron-Cohen et al., 2009; Surén et al., 2013; Gilberg, Cederlund, Lamberg, \& Zeijlon, 2006; Özerk, 2016).

The previous studies in Norway have focused on the prevalence rates among a specific age group at the state level (Gundersen \& Hem, 2005; Stoltenberg et al., 2010; Surén et al., 2012; 2013).

This study is the first of its kind and investigates the prevalence of autism/ASD among the preschool-age children (1-5 years old) and school-age children (6-16 years old) along with the gender differences in the prevalence of autism/ASD in the capital city of Oslo, Norway from 2012 to 2016. 


\section{Autism/ASD and manuals}

Autism is a neurodevelopmental disorder and autism spectrum disorder (ASD) encompasses behavior related challenges at different level of severity. Children with autism/ASD demonstrate varying degrees of difficulties in social interaction, social communication, verbal and nonverbal communication along with restricted, repetitive, and stereotyped patterns of behaviors, interests, and activities (NAS, 2018). Moreover, Autism, along with its subtypes and ASD are medical terms, which belong to the diagnostic categories of complex neurodevelopmental disorders. "A diagnosis of ASD is based on descriptions and observations of behavior. [...] there is much evidence that Autism is a neurodevelopmental disorder with a very strong genetic component..." (Lord \& Bishop, 2010: 3-4).

Two diagnostic and classifications manuals, ICD-10 and DSM-5 are being utilized by specialized health professionals to identify the diagnosis of autism (autistic disorder) and ASD. ICD-10 stands for the $10^{\text {th }}$ version of the International Classification of Diseases (ICD) and was published by the World Health Organization in 1990 and all the members agreed to use it from the year 1994 (WHO, 1994). Its $11^{\text {th }}$ version, ICD-11, was recently introduced (WHO, 2018). Furthermore, DSM- 5 is the $5^{\text {th }}$ version of the Diagnostic and Statistical Manual of Mental Disorders (DSM), developed by the American Psychiatric Association (APA). DSM-5 replaced DSM-IV in the year 2013 (APA, 2013).

\section{Prevalence studies in the US}

The majority of the prevalence studies regarding autism/ ASD are conducted in the US. The prevalence statistics in the United States are underpinned by the real representative data and estimates from the available representative data. The American Centers for Disease Control and Prevention $(C D C)$ is the primary and the most reliable source for the prevalence statistics in the USA. It receives federal funds and also provides funding for the studies and programs in order to monitor and report data concerning the diseases. Additionally, the Autism and Developmental Disabilities Monitoring (ADDM) network is a group of programs funded by the CDC to estimate the number of children with autism spectrum disorder (ASD) residing in diverse regions of the United States (CDC 2016). The ADDM consists of several network sites, which collect the required data. The ADDM surveillance system has ascertained ASD among the 8-year-old children through a systematic review of clinical and educational records in accordance with the CDC's surveillance program called as 'Metropolitan Atlanta Developmental Disabilities Surveillance Program (MADDSP)'.

The ADDM Network sites, acquire data regarding the children's population with autism/ASD. It compares the number of children who are diagnosed with autism/ASD in a certain number of sites/areas in a certain number of states of the US since 2000, and subsequently identify the alteration in the number of children with autism/ASD. The biannual data from these sites/areas are being utilized to estimate the prevalence rates of autism/ASD among the 8-year-old children in America. During the period of 20002012, the ADDM Network conducted seven biannual surveillance studies among the eight-year-old children. Moreover, the study conducted in 2000 included the children who were born in 1992 and the study in 2012 included the children who were born in 2004. The lowest number of eight-year-old children in these studies was 172335 in 2004 and the highest number of 8-year-old children was 407578 in 2002. The results from these studies revealed that 1 in 150 children in the years 2000 and 2002, 1 in 125 children in 2004, 1 in 110 children in 2006 in the study sites was diagnosed with autism/ASD (CDC, 2014). First time in the history of ADDM Network Surveillance Studies, it was found that 1 in 88 American children was diagnosed with autism/ ASD in the 14 study sites in the year 2008 (CDC, 2008). This was the first time that one out of less than 100 children received a diagnosis of autism/ASD based on the diagnostic criteria from the Diagnostic and Statistical Manual of Mental Disorders, 4th Edition-TR (DSM IV-TR, APA, 2000). In accordance with the estimated prevalence, Autism was identified as the fastest-growing developmental disability in the US. Furthermore, a similar ADDM Network Surveillance Studies revealed a higher rate of prevalence: 1 in 68 children in 2012 ((Blumberg et al., 2013; Christiansen et al., 2016; Zablotsky, Maenner, Schieve, \& Blumberg, 2015) and 1 in 59 in 2014 (Baio et al, 2018).

\section{International Prevalence studies}

According to the studies from other countries, during the recent decades, there has been a considerable rise in the prevalence rate of autism/ASD. An Australian study (Williams, MacDermott, Ridley, Glasson, \& Wray, 2008) highlighted a significant rise in the prevalence rates among 1-16-year-old children from 2003 to 2005. Among 0-5-yearold children 1 in 455 and among 6-12-year-old children 1 in 160 had diagnosis of autism/ASD in 2005.

A Canadian study (Ouellette-Kuntz, Coo, \& Gorski, 2012) highlighted that the prevalence rate of autism/ASD among the 2-14-year-old children has been rising in three regions of Canada (Newfoundland and Labrador, Prince Edward Island, and Southern Ontario). Moreover, in 2003, the prevalence rate was identified as 1 in 204, this subsequently increased to 1 in 109 in the year 2008. For 2-4-year-old preschool children the prevalence rate was 1 in 159 and for 5-14-year-old school-age children 1 in 101 had the diagnosis of autism/ASD in 2008.

In Israel, the nationwide prevalence rate of autism/ASD among the children between 1-12 years (Davidovitch, Hemo, Manning-Courtney, \& Fombonne, 2013) increased dramatically from 2004 to 2010 . The study also revealed that, while in 2004, 1 in 1533 of 1-12-year-old children was diagnosed with autism, the rate increased to 1 in 196 in 2010.

A comprehensive study of the prevalence of autism/ASD in three metropolitan areas of the Netherlands revealed that in Eindhoven 1 in 44, in Haarlem 1 in 119 and in Utrecht 1 in 175 children between the age of 4-16-years were diagnosed with Autism/ASD (Roelfsema et al., 2012).

A nation-wide representative study in U.K. showed that 1 in 100 children between the age group of 5-10-year-old and 1 in 125 among the 11-16-year-old children was diagnosed with autism/ASD (Green et al., 2005)

A citywide study in the city of Leon (Guanajuarto) in Mexico (Fombonne et al., 2016) revealed that among the age group of 8-year-old children, 1 in 115 was diagnosed with autism/ASD. Two Japanese studies examined the prevalence of autism/ASD in two cities in Japan. According to Honda, Shimizu, and Rutter (2005), 1 in 266 children at the age of 5 was diagnosed with autism/ASD in the city of Yokohama. In the city of Toyota, Kawamura, Takahashi, and Ishii (2008) discovered that 1 in 55 among 5-8-year-old children was diagnosed with autism/ASD. Furthermore, another study conducted in one of the Asian cities revealed a higher rate of autism/ASD than Japan. In the Goyang city, situated in South Korea, it was found that 1 among 38 children between the age of 8-12 years, had autism/ASD (Kim et al., 2011).

Prevalence studies of autism/ASD Scandinavian / Nordic countries

A Danish population study (Parner, Schendel, \& Thorsen, 
2008) discovered that the prevalence rates of autism/ASD among the Danish children are quite high: 1 in 162 among those who were diagnosed at the age of 5.3, 1 in 135 among those who were diagnosed at the age of 5.8, and 1 in 122 among those who were diagnosed at the age of 5.9. This study utilized the numerals of the factually registered incidences of autism in a national registry.

Another Danish study by Hansen, Schendel and Parner, (2015) found that among children who were born between 1990 and 1991 and who were diagnosed during the period from 1996 thru 2011, 1 in 102 had autism/ASD.

In a study in the Faroe Islands, The Kingdom of Denmark, the researchers found that 1 among 185 children between the age of 8 and 17 was diagnosed with autism/ASD (Ellefsen, Kampmann, Billstedt, Gillberg, \& Gillberg, 2007).

One of the earlier citywide studies of autism/ASD in Scandinavia was conducted by Gillberg et. al. (2006) in the city of Gothenburg. The results of this research showed that 1 in 125 among 7-12-year-old children and 1 in 163 among 13-18-year-old children had autism/ASD.

Furthermore, another Swedish study was conducted on children aged between 0-17 years old in the Stockholm County (Idring et al., 2012). This was a record-linkage study including all individuals aged between $0-17$ who resided for at least 4 years in the Stockholm County during the year 2001 to 2007. Consecutively, in a sample size of 444154 children between the ages 0-17 years, they found 5,100 children had ASD. Therefore, this implies that 1 in 87 children under the age of 17 years was diagnosed with autism/ ASD.

A statewide prevalence study in Finland (Hinkka-Yli-Salomäki et al., 2014) found that 1 in 186 children born between 1987 and 2005 was diagnosed with autism/ASD. A regional Finnish study concluded that I in 119 children at the age of 8 had autism/ASD (Kielinen, Linna, \& Moilanen 2000).

In Iceland, Saemundsen, Magnússon, Georgsdóttir, Egilsson, and Rafnsson (2013) conducted a nationwide study of the prevalence of clinically confirmed ASD diagnosis. This study was conducted among 22229 children, of which 11424 were males and 10805 were females. They were between the age of 8 to 15 years, born during the year 1994-1998. In the study, autism spectrum diagnosis included Childhood Autism F84.0 in ICD-10, Autistic Disorder in DSM-IV, Asperger's Syndrome F84.5 in ICD-10, Asperger's Disorder in DSM-IV and other subtypes: F84.1, F84.8 and F84.9 in ICD-10 and Pervasive Developmental Disorders (PDD), not otherwise specified in DSM-IV. F84.4 in ICD10 was not used. It was discovered that 197 males out of 11424 and 70 females out of 10805 were diagnosed with ASD. The results of the study revealed that a total of 267 children were diagnosed with ASD, which consisted of 197 boys and 70 girls. Hence, this equates to a prevalence rate of 1 in 83 among the Icelandic children between the age of 8-15 years old. With reference to the gender differences, the study revealed that 1 in 58 males and 1 in 154 females among the children population had autism/ASD, with the male-to-female ratio being 2.81:1.

\section{Prevalence of autism/ASD in Norway}

During the 1980s and 1990s, 1 in 1,000 children received a diagnosis of autism/ASD in Norway (Gundersen \& Hem, 2005). A nationwide prevalence study, among the 0 to 10-year-old Norwegian children highlighted that 1 in 166 had autism/ASD in 2010 (Stoltenberg et al., 2010), and 1 in 125 children of the age 11, were diagnosed with autism/ ASD in Norway during the year 2012 (Surén et al., 2012; 2013).
A recent countrywide study regarding the prevalence of autism among 1-16-year-old children showed that 1 in 192 boys and 1 in 695 girls had autism/ASD in 2016 in Norway. However, the prevalence rates differed among the preschool-age children (1-5-year-old) and school-age children (6-16-year-old). Moreover, among preschool-age children 1 in 349 males and 1 in 1594 females had autism/ASD in 2016. On the contrary, 1 in 157 males and 1 in 544 females had autism/ASD at the school-age. The investigators introduced the term "school-age effect" due to the fact, that 2.22 times more school-age boys than preschool-age boys and 2.93 times more school-age girls than preschool-age were diagnosed with autism/ASD in 2016 (Özerk \& Cardinal, 2018 in press).

The aforementioned Norwegian studies are informative. Nevertheless, there is a need for citywide, municipality-wide, and county-wide prevalence studies to advise and assist the local authorities in their long-term planning of public services. Besides, databased planning of educational and health care services is required, for example, it is important to develop a training and/or recruitment of qualified staff in order to implement evidence-based interventions programs and establish adaptive physical environmental conditions in the kindergartens and schools.

This study presents a citywide prevalence of autism/ASD among 1-16-year-old children in the capital city of Oslo from 2012 to 2016. Oslo is the capital city of Norway, a municipality and at the same time one of the country's 19 counties. Moreover, Oslo has its own school administration, kindergarten administration (predominantly for 1-5-year-old children) and healthcare administration. Furthermore, kindergartens are not compulsory for 1-5-yearold children. Parents pay the tuition fees, but the kindergartens are heavily subsidized to achieve the country's officially declared goal of 'enrollment opportunity for all children'. Children between the ages of 6 to 16 years are the students who enroll the compulsory 10-year basic school. Oslo's child population for 1-16-year-old children in 2016 was 108238 and comprised of 8.7\% Norwegian children (938 847) belonging to the same age group that year (SSB, befolkningsstatistikk, 2017; Oslo Kommune statistikk, 2017).

\section{Method and Data Sources}

The present study investigates the prevalence of autism/ ASD among 1-16-year-old children in the capital city of Oslo in Norway. Norway has universal health care services, which provide free health care services. Moreover, the country has a well-established national patient registry.

In order to study the rate of prevalence in the city of Oslo, the raw data was gathered from the Norwegian Patient Registry (NPR, Dated 15.06.17-17/2362-9), Norwegian Statistics (SSB, befolkningsstatistikk, 2017) and Oslo Statistics (Oslo Kommune statistikk, 2017). The raw data consists of Oslo's children population of 1-16 years old along with the ones who were registered to be diagnosed with Autism/ ASD between the year 2012-2016, their age and gender are in accordance with the ICD-10's F84.0 Childhood Autism and F84.5 Asperger Syndrome. According to their rules the NPR did not provide the number of children with autism/ ASD in any age group in a county or city, if the number of children were less than 5 . Additionally, the contract specified that if no children were diagnosed with autism/ASD in any age group in a county or city in a given year, the row data from the NPR will account this as zero. Furthermore, if the number of children diagnosed with Autism/ASD in a county or city in an age group in a given year is five or more, the row data will note this. Hence, this implies that 
Table 1. Children population in different age and gender groups, the population of children with Autism/ASD and prevalence rates in Oslo from 2012 to 2016

\begin{tabular}{|c|c|c|c|c|c|c|c|c|c|c|}
\hline \multicolumn{11}{|c|}{ Number of males $(M)$ and females $(F)$ in different age groups and the total $(T)$} \\
\hline Year & & $1-5 \mathrm{M}$ & $1-5 \mathrm{~F}$ & $1-5 \mathrm{~T}$ & $6-16 \mathrm{M}$ & $6-16 \mathrm{~F}$ & $6-16 \mathrm{~T}$ & $1-16 \mathrm{M}$ & $1-16 \mathrm{~F}$ & $1-16 \mathrm{~T}$ \\
\hline \multirow[t]{3}{*}{2012} & Population & 21156 & 20392 & 41548 & 30424 & 29207 & 59631 & 51580 & 49599 & 101179 \\
\hline & Aut./ASD & 29 & 4 & 33 & 106 & 27 & 133 & 135 & 31 & 166 \\
\hline & Rate: 1 in & 730 & 5098 & 1259 & 287 & 1082 & 448 & 382 & 1600 & 610 \\
\hline \multirow[t]{3}{*}{2013} & Population & 21443 & 20446 & 41889 & 30991 & 29847 & 60838 & 52434 & 50293 & 102727 \\
\hline & Aut./ASD & 39 & 4 & 43 & 124 & 30 & 154 & 163 & 34 & 195 \\
\hline & Rate: 1 in & 550 & 5112 & 974 & 250 & 995 & 395 & 322 & 1479 & 521 \\
\hline \multirow[t]{3}{*}{2014} & Population & 21669 & 20684 & 42353 & 31679 & 30454 & 62133 & 53348 & 51138 & 104486 \\
\hline & Aut./ASD & 29 & 4 & 33 & 123 & 32 & 155 & 152 & 36 & 186 \\
\hline & Rate: 1 in & 747 & 5171 & 1283 & 258 & 952 & 401 & 351 & 1421 & 562 \\
\hline \multirow[t]{3}{*}{2015} & Population & 21600 & 20809 & 42409 & 32580 & 31303 & 63883 & 54180 & 52112 & 106292 \\
\hline & Aut./ASD & 43 & 7 & 50 & 188 & 48 & 236 & 231 & 55 & 286 \\
\hline & Rate: 1 in & 502 & 2973 & 848 & 173 & 652 & 271 & 235 & 947 & 372 \\
\hline \multirow[t]{3}{*}{2016} & Population & 21530 & 20662 & 42192 & 33562 & 32484 & 66046 & 55092 & 53146 & 1082238 \\
\hline & Aut./ASD & 56 & 12 & 68 & 217 & 52 & 269 & 273 & 64 & 337 \\
\hline & Rate: 1 in & 384 & 1722 & 620 & 155 & 625 & 246 & 202 & 830 & 321 \\
\hline
\end{tabular}

Aut./ASD: Children with autism/autism spectrum disorders

if the number of children in an age group who received a diagnosis of autism/ASD in Oslo was 1, 2, 3, or 4, the raw data did not account this as a means to preserve anonymity. Moreover, between the year 2012-2014, there was missing data from the NPR concerning the females between the age of 1-5-year-old, diagnosed with autism/ ASD (ICD-10: F84.0 Childhood Autism and F84.5 Asperger syndrome). Hence, this proves that there were either 4 or less than 4 females between the age of 1- 5 years, who were diagnosed with autism/ASD in the city of Oslo. For 2013 and 2014, I provided the actual numbers acquired from Oslo's local township administration and pedagogical and psychological services. Hence, in this paper, only four female children in the age group of 1-5 years during the year 2012, had autism/ASD disorder.

\section{Results}

\section{Prevalence of autism/ASD in the capital city of Os/o}

Table 1 presents an overview of the children population, the autism/ASD population, the age groups, gender categories and the prevalence rates of autism/ASD from 2012 to 2016 .

The data in the table (Table 1) highlights the total number of children who were diagnosed with autism/ASD during the period, 2012 to 2016 along with the distribution of children with autism/ASD in accordance with their age group, during the same period. Furthermore, the table (Table 1) shows that the prevalence rates are altering according to the age, gender and year. In the following sections, I'll initially present a detailed analysis of the prevalence of autism/ASD among the male and female population belonging to the preschool-age children and school-age children in the city of Oslo.
Figure 1 illustrates the increase in the number of children with autism/ASD in Oslo during the five-year period from 2012 to 2016.

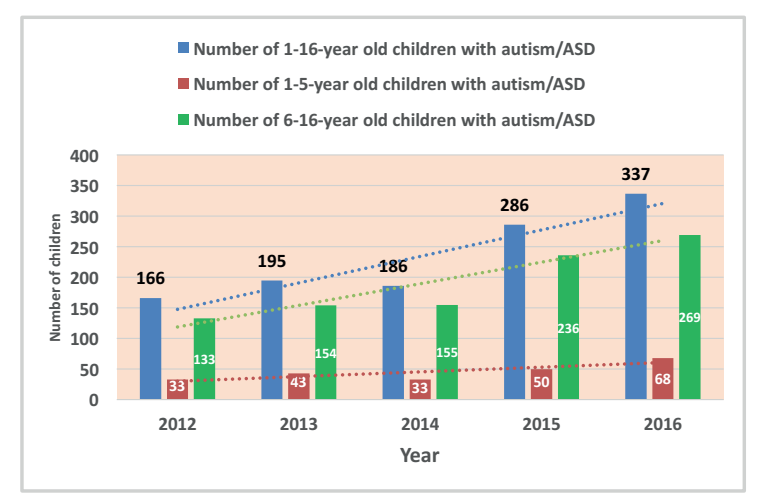

Figure 1. Total number of 1-16-year-old children with autism/ASD in Oslo

Hence, according to the trend-lines, the number of 1-16-year-old children with autism/ASD is increasing. It is clear that the trend is ascending among the age group of 1-16-year-old children with autism/ASD along with its sub-categories of 1-5-year-old and 6-16-year-old children. During the year 2012-2016, the number of children with autism/ASD in the age group of 1-16-year-old has doubled, in the capital city of Oslo.

Prevalence rates of Autism/ASD among preschool-age children in Os/o

The preschool-age children belong to the 1-5-year-old category. The following figure (figure 2 ) highlights the alter- 
ation in the prevalence rates in the male and female population among the preschool-age from 2012 to 2016:

As one may see in the figure (figure 2), there has been an increase in the prevalence rates of autism/ASD among the 1-5-year-old males and females from 2012 to 2016. While 1 in 730 males in 2012 had autism/ASD, this rate increased to 1 in 384 in 2016 . Hence, the rate of increase is $90 \%$.

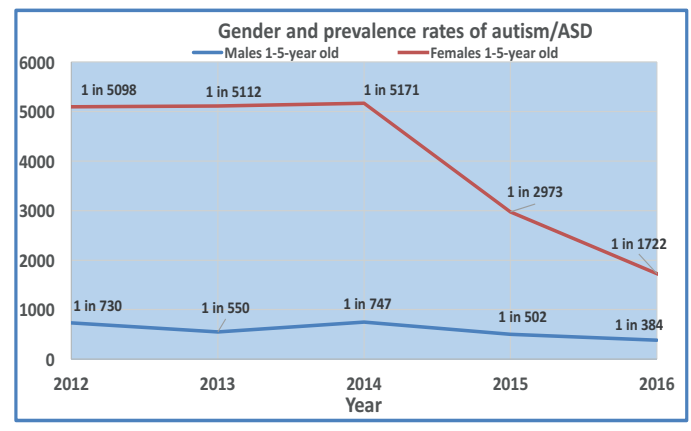

Figure 2. Prevalence rates of Autism/ASD among 1-5-yearold males and females in Oslo

In 2012 only 1 in 5098 females was diagnosed with autism/ ASD among the preschool-age group of 1-5-year-old. Subsequently, this rate increased to 1 in 1722 in 2016, hence the increase is $196 \%$. Moreover, the male-to-female ratio in 2012 was 6.98:1. Subsequently, it decreased to 4.48:1 in 2016.

Therefore, these results show that not only the number of 1-5-year-old children with autism/ASD increased but also the prevalence rates of autism/ASD increased from 2012 to 2016. Moreover, the gender gap is narrowing.

\section{Prevalence of autism/ASD among school-age children in Oslo}

The study comprises of another subgroup of 6-16-yearold children with autism/ASD. These children belong to the school-age category. Furthermore, they enroll in the compulsory 10-year Norwegian public school. The following figure (Figure 3 ) shows the prevalence rates of autism/ ASD among the school-age males and females in the city of Oslo.

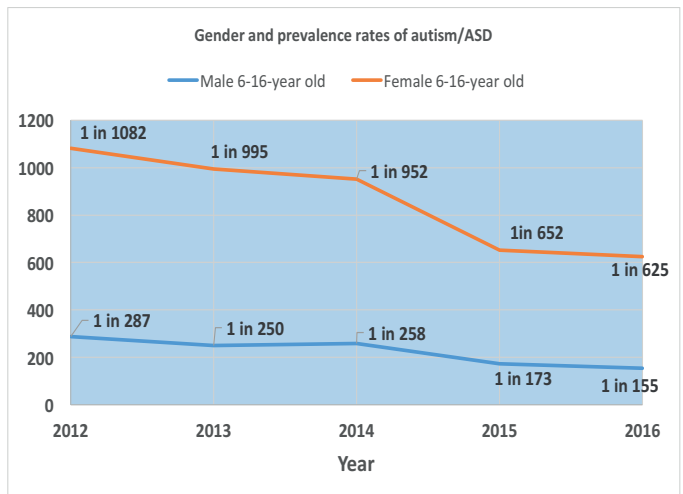

Figure 3. Prevalence rates of autism/ASD among 6-16-year-old males and females in Oslo

The results show that there has been an increase in the prevalence rates of autism/ASD among 6-16-year-old males and females from 2012 to 2016 . While 1 in 287 males in 2012 had autism/ASD, this rate increased to 1 in 155 in 2016 . Hence, the rate of increase is $85 \%$.
In the year 2012, only 1 in 1082 females at school-age in Oslo was diagnosed with autism/ASD. In 2016 this rate increased to 1 in 625 . Hence, the increase rate is $73 \%$. Contrary to the preschool-age children, the gender gap is not narrowing among school-age children with autism/ASD. The male-to-female ratio in 2012 was 3.77:1, in 2013 it was 3.98:1, and in 2014 it was 3.69:1 and 3.77:1 and 4.03:1 in 2015 and 2016, respectively. There is a variable trend that shows a slight rise in the male-to-female ratio to 4.03:1 in 2016 compared to 3.77:1 in 2012.

The likelihood for preschool-age children to get autism/ASD diagnosis as school-age children

As mentioned earlier, several international studies discovered that more school-age children have been diagnosed with autism/ASD than the preschool-age. A Norwegian study conducted by Özerk and Cardinal (2018 in press) replicated this tendency and called it the "school-age effect". The following figures represent the rates of autism among females and males of the school-age, compared to the males and females of the preschool-age, respectively.

In accordance with the figure (figure 4), during the five years, the rate of autism/ASD among school-age males is higher than the preschool-age males. Hence, in 2012 the rise was $254 \%$, and in the subsequent years, it was $220 \%$ in $2013,289 \%$ in $2014,290 \%$ in 2015 and $247 \%$ in 2016 respectively.

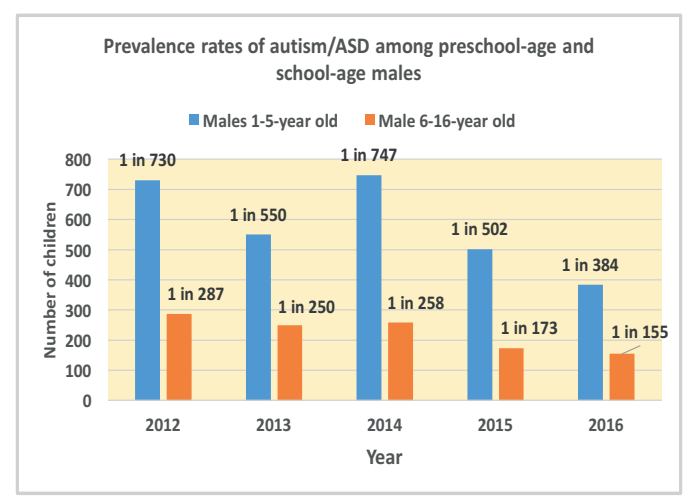

Figure 4. The rise of autism/ASD prevalence rates among males from preschool-age to school-age

This implies that there is a likelihood that between $220 \%$ and $290 \%$ higher rates of males were diagnosed with autism/ASD at the school-age compared to the preschool age males.

The following figure presents the results for females at the school-age.

The tendency is quite clear: More females in school-age are diagnosed with autism/ASD than females in the preschool-age. The prevalence rate of autism/ASD among the school-age females was $471 \%$ higher than prevalence rates among the preschool-females in 2012, and the rise in 2013 accounts to $513 \%$. In the subsequent years, the increase in the prevalence rate of autism/ASD among preschool-age females to prevalence rate of autism/ASD among schoolage females was approximately $543 \%$ in $2014,455 \%$ in 2015 and $275 \%$ in 2016. In other words, higher rates of autism/ASD was observed among the school-age females compared to the preschool-age females. This means that there is a likelihood that between $275 \%$ and $543 \%$ higher rates of females can be diagnosed with autism/ASD at the school age compared to the preschool-age females. 


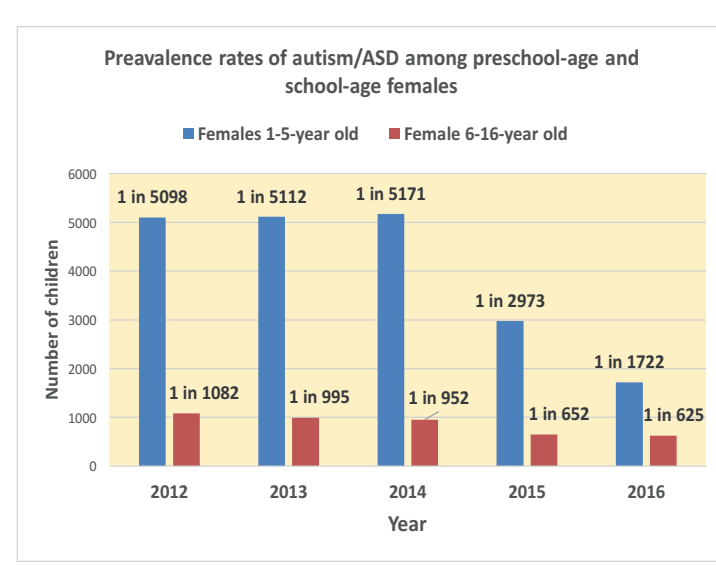

Figure 5. The rise of autism/ASD prevalence rates among females from preschool-age to school-age

\section{Discussion and suggestions}

This first comprehensive study of prevalence rates of autism/ASD (ICD-10: F84.0 Childhood Autism and F84.5 Asperger Syndrome) in the capital city of Oslo, Norway, shows a clear tendency: The number of 1-16-year-old children with autism/ASD and the prevalence rates of autism/ ASD among 1-16-year-old children is increasing.

In 2012 there were 166 children and in 2016 there were 337 children between the age of 1-16 years with autism/ ASD in Oslo. This increase indicates that the number of children with autism/ASD (ICD-10: F84.0 Childhood Autism and F84.5 Asperger Syndrome) in Oslo doubled from 2012 to 2016.

Moreover, when we look at the gender differences in different age groups, we can see that the prevalence rate of autism/ASD has increased: 1 in 730 males in the 1-5-yearold group had autism/ASD in 2012 and it rose to 1 in 384 in 2016, with the increase being approximately $90 \%$. In the case of 1-5-year-old females, it was 1 in 5098 in 2012, and subsequently, 1 in 1722 in 2016 . Even though the rates have risen, one has to be cautious since the number of 1-5-year-old males and females are low: 29 in 2012 and 56 in 2016 for males, and 4 in 2012 and 12 in 2016 for females.

In the case of 1-5-year-old children, the male-to-female ratio in 2012 was 6.98:1. It further decreased to 4.48:1 in 2016. Therefore, the results reveal that not only the number of children with autism/ASD increased but also its prevalence rate has increased from 2012 to 2016. Moreover, the gender gap is narrowing for the 1-5-year-old age group.

The school-age group: While 1 in 287 males in 2012 had autism/ASD, this rate increased to 1 in 155 in 2016, the rate of increase being 85\%. In 2012 there were 106 school-age children (6-16-year-old) with autism/ASD. Subsequently, in 2016 the number increased to 217. Moreover, in the year 2012, there were 27 school-age females (6-16-yearold) with autism/ASD in Oslo. The number increased to 52 in 2016. This is equivalent to $93 \%$ increase. Furthermore, in 2012, 1 in 1082 school-age females had autism/ASD. In 2016 the prevalence rate for school-age females became 1 in 625 . The increase is $73 \%$.

The male-to-female ratio for the school-age group was $3.77: 1$ in 2012. It became 4.03:1 in 2016. According to this study, the gender gap between males and females with respect to autism/ASD diagnosis at school-age from 2012 to 2016 has not been reduced.

Compared to the results of the aforementioned countrywide prevalence study, Oslo has a lower rate of children with autism/ASD than the average of Norway. The prevalence rate of autism/ASD among 1-16-year-old children in the entire country was 1 in 192 for males and 1 in 695 for females in 2016. In Oslo, during the year 2016, the rate was 1 in 202 for males and 1 in 830 for females. When we compare the prevalence rates of the subgroups of children, it can be observed that among 1-5-year-old males 1 in 349 and among 1-5-year-old females 1 in 1594 had autism/ ASD in Norway during the same year. In Oslo, it was 1 in 384 males and 1 in 1722 females. Therefore, these findings highlight that the prevalence rates in Oslo are lower than the average of Norway.

In the entire country, 2.22 times more males and 2.93 times more females at the school-age (6-16-year-old) had autism/ASD than the preschool-age (1-5-year-old) in 2016. In Oslo, 1.48 times more males and 1.76 times more females had autism/ASD at the school-age than the preschool-age. These findings suggest that the factor called as the 'school-age-effect' can be observed in the prevalence rates of the city of Oslo: Higher rates of school-age children (6-16-year-old) had the diagnosis of autism/ASD than the preschool age (1-5-year-old) children.

According to these findings, there is a need for a comprehensive educational and healthcare planning for the treatment, training, and teaching of the increasing number of 1-16-year-old children with autism/ASD in Oslo. Moreover, such plans need to prioritize competence development and capacity building among staff members. There is no doubt that 337 children with autism/ASD diagnosis need specially trained teachers, special education teachers, preschool teachers, teacher aid and other professionals, for example, occupational therapist, social educators and speech-language pathologists who are involved in the treatment, training, and teaching of this group of children. This study only has data for two age groups, hence this stands as a limitation. Additionally, this study does not observe the possible differences between diverse groups with respect to the prevalence rates among children from the different area of residence in Oslo, age, gender, socioeconomic, language and ethnic backgrounds. Hence, additional research is required in order to address the possible relation of these factors for varied prevalence rates of autism/ASD. There is no doubt that the results of this study can be an important help for the educational and healthcare authorities to make informed decisions regarding the planning and implementation of the evidence-based and culture-sensitive treatment, training, and teaching methods in inclusive environments for these children by specially trained staff.

\section{Acknowledgment}

The author received funding for this study from "Osloforskning" and the Department of Education, University of Oslo.

\section{References}

American Psychiatric Association. (1994). Diagnostic and statistical manual of mental disorders (4th ed.). Washington, DC: APA Press.

American Psychiatric Association. (2000). Diagnostic and statistical manual of mental disorders (4th ed., text rev.). Washington, DC: APA Press.

American Psychiatric Association. (2013). Diagnostic and statistical manual of mental disorders (5th ed.). Washington, DC: APA Press.

Autism Society of USA. (2016). What is Autism? Retrieved from http://www.autismsociety.org/what-is/

Baio J, Wiggins L, Christensen, D, L, et al. (2018). Prevalence of Autism Spectrum Disorder Among Children Aged 
8 Years - Autism and Developmental Disabilities Monitoring Network, 11 Sites, United States, 2014. MMWR Surveill Summ 2018; 67(No. SS-6):1-23. DOI: http://dx.doi.org/10.15585/mmwr.ss6706a1

Baird, G., Simonoff, E., Pickles, A., Chandler, S., Loucas, T., Meldrum, D., \& Charman, T. (2006). Prevalence of disorders of the autism spectrum in a population cohort of children in South Thames: The specia needs and autism project (SNAP). Lancet, 368, 210215.

Baron-Cohen, S., Scott, F. J., Allison, C., Williams, J., Bolton, P., Matthews, F. E., \& Brayne, C. (2009). Prevalence of autism-spectrum conditions: UK school-based population study. The British Journal of Psychiatry, 194, 500-509. doi:10.1192/bjp.bp.108.059345

Bishop, D.V.M., Whitehouse, A. J. O., Watt, H. J. \& Line, E. A. (2008). Autism and diagnostic substitution: evidence from a study of adults with a history of developmental language disorder. Developmental Medicine \& Child Neurology, 50, 341-345.

Blumberg, S. J., Bramlett, M. D., Kogan, M. D., Schieve, L. A., Jones, J. R., \& Lu, M. C. (2013).Changes in prevalence of parent-reported autism spectrum disorder in school-aged U.S. children: 2007 to 2011-2012 (National Health Statistics Reports No. 65). Hyattsville, MD: National Center for Health Statistics.

Cardinal, D. \& Griffiths, A-J. (2016). Summary of findings. Report presentet at the Inagural Disability Summit. Orange: Chapman University, Thompson Policy Institute.

Cardinal, D., \& Fraumeni-McBride, J. (2017). Increase in rate of autism likely a factor of definition. Report present ed at the Inaugural Disability Summit. Orange, CA Chapman University, Thompson Policy Institute.

CDC (2008). Prevalence of autism. http://www.cdc.gov/ ncbddd/autism/data.html (Accessed December, 10, 2008).

CDC (2014). Autism and Developmental Disabilities Monitoring Network Surveillance Year 2010 Principal Investigators. Prevalence of autism spectrum disorder among children aged 8 years-Autism and Developmental Disabilities Monitoring Network, 11 sites, United States, 2010. MMWR Surveillance Summaries 2014; 63(No. SS-2). Atlanta, GA: Centers for Disease Control and Prevention.

CDC (2016). Centers for Disease Control and Prevention. Autism Spectrum Disorder (ASD). Data and Statistics. http://www.cdc.gov/ncbddd/autism/data.html (Accessed June 16th, 2016).

Chakrabarti, S. \& Fombonne, E. (2005). Pervasive developmental disorders in preschool children: confirmation of high prevalence. American Journal of Psychiatry, 162, 1133-1141.

Christensen, D. L, Baio, J., Braun, K. V., Bilder, D., Charles, J., Constantino, J. N., ... Yeargin-Allsopp, M. (2016). Prevalence and characteristics of autism spectrum disorder among children aged 8 years-Autism and Developmental Disabilities Monitoring Network, Sites, United States, 2012. Morbidity and Mortality Weekly Report Surveillance Summaries 2016 65(No. SS-3), 1-23. doi:http://dx.doi.org/10.15585/ mmwr.ss6503a1

Davidovitch, M., Hemo, B., Manning-Courtney, P., \& Fombonne, E. (2013). Prevalence and incidence of autism spectrum disorder in an Israeli population. Journal of Autism and Developmental Disorders, 43, 785-793. doi:10.1007/s10803-012-1611-z

Eikeseth, S. (2014). God og verdig omsorg. Viten. https:// www.aftenposten.no/ viten/i/vm73X/God-og-verdig-omsorg. 09. April, 2014
Ellefsen, A., Kampmann, H., Billstedt, E., Gillberg, I. C. \& Gillberg, C. (2007). Autism in the Faroe Islands. An Epidemiological Study. Journal of Autism and Developmental Disorders, 37(3), 437-444. DOI 10.1007/ s10803-006-0178-y 123

Elsabbagh, M., Divan, G., Koh, Y.-J., Kim, Y. S., Kauchali, S., Marcín, C., Montiel-Nava, C., Patel, V., Paula, C.S., Wang, C., Yasamy, M.T., \& Fombonne, E. (2012). Global prevalence of autism and other pervasive developmental disorders. Autism Research, 5(3), 160-179.

Fombonne, E. (2005). Epidemological studies of pervasive developmental disorders. I F. Volkmar, R. Raol, A. Klin \& D. Cohen (eds.). Handbook of Autism and pervasive developmental disorders. Hoboken, N.J. Wiley.

Fombonne, E. , Marcin, C., Manero, A. C., Bruno, R., Diaz, C., Villalobos, M., Ramsay, K. \& Nealy, B. (2016). Prevalence of Autism Spectrum Disorders in Guanajuato, Mexico: The Leon survey. Journal of Autism and Developmental Disorders. 46(5), 1669-1685.

Gilberg, C., Cederlund, M., Lamberg, K., \& Zeijlon, L. (2006). Brief report: "The autism epidemic." The registered prevalence of autism in a Swedish urban area. Journal of Autism and Developmental Disorders, 36(3), 429-435.

Green, H., McGinnity, A., Meltzer, H., Ford, T. \& Goodman, R. (2005). Mental health of children and young people in Great Britain. Gosport, UK: Palgrave Macmillan/ National Statistics.

Gundersen, T. \& Hem K.-G, (2005). Brukerundersøkelse blant personer med diagnose innen autismespekteret. Erfaringer med Autismenettverket [User survey among people with a diagnosis within the autism spectrum. Experiences with Autism Network]. 09-15 STF78 A054504.

Hansen, S. N., Schendel, D. E. \& Parner, E. T. (2015). Explaining the Increase in the Prevalence of Autism Spectrum Disorders The Proportion Attributable to Changes in Reporting Practices. Journal of American Medical Association Pediatrics. 169(1), 56-62. DOI:10.1001/jamapediatrics.2014.1893.

Hart, J. E., \& Malian, I. (2013). A statewide survey of special education directors on teacher preparation and licentiate in autism spectrum disorders: A model for university and state collaboration. Internationa Journal of Special Education, 28, 4-13.

Hinkka-Yli-Salomäki, S., Banerjee, P.N., Gissler, M., Lampi, K. M., Vanhala, R., Brown, A. S., \& Sourander, A. (2014) The incidence of diagnosed autism spectrum disorders in Finland, Nordic Journal of Psychiatry, 68:7, 472-480, DOI: 10.3109/08039488.2013.861017

Honda, H., Shimizu, Y., \& Rutter, M. (2005). No effect of MMR withdrawal on the incidence of autism: A total population study. Journal of Child Psychology and Psychiatry, 46, 572-579.

Howlin, P. (2008). Autism and diagnostic substitution. Developmental Medicine \& Child Neurology. 50(5), 325325.

Idring, S., Rai, D., Dal, H., Dalman, C., Sturm, H., Zander, E., . . . Magnusson, C. (2012). Autism spectrum disorders in the Stockholm youth cohort: Design, prevalence and validity. PLOS ONE, 7(7). e41280. doi:10.1371/ journal.pone.0041280.

Isaksen, J. (2010). Alvorlige diagnoser krever seriøs behandling. Kronikk i Forskning.no. Lørdag 24. April 2010

Kawamura, Y., Takahashi, O., \& Ishii, T. (2008). Reevaluating the incidence of pervasive developmental disorders: Impact of elevated rates of detection through implementation of an integrated system of screen- 
ing in Toyota, Japan. Psychiatry and Clinical Neuroscience, 62, 152-159.

Kielinen, M., Linna, S. L., \& Moilanen, I. (2000). Autism in Northern Finland. European Child and Adolescent Psychiatry, 9, 162-167.

Kim, Y. S., Leventhal, B. L., Koh, Y. J., Fombonne, E., Laska, E., L., Cheon, K-A., Kim, S-J., Lee, H-K., Song, D-H \& Grinker, R. R. (2011). Prevalence of Autism Spectrum Disorders in a Total Population Sample. American Journal of Psychiatry, 168(9), 904-912.

Lauderdale-Littin, S. \& Brennan, M. (2018). Evidence-Based Practices in the Public School: The Role of Preservice Teacher Training. International Electronic Journal of Elementary Education. Vol. 10, Issue 3, 369-375. DOI: 10.26822/iejee.2018336195

Lord, C. \& Bishop, S. L. (2010). Autism Spectrum Disorders. Diagnosis, Prevalence, and Services for Children and Families. Social Policy Report, 24(2), 1-26.

NAS (2018). What is autism? Retrieved from http://www.autism.org.uk/about/what-is.aspx. Guelph, Ontario: National Autistic Society.

Norwegian Statistics (2017). Statistics Norway. Retrieved from http://www.ssb.no

Odom, S. L. Boyd, B. A., Hall, L. J., \& Hume, K. (2010). Evaluation of comprehensive treatment models for individuals with ASD. Journal of Autism and Developmental Disorders, 40, 425-436.

Oslo Kommune (2017) http://statistikkbanken.os/o.kommune.no/webview/

Ouellette-Kuntz, H., Coo, H., \& Gorski, D. (2012). Findings from the National Epidemiologic Database for the Study of Autism in Canada (NEDSAC). Changes in the Prevalence of autism spectrum disorders in Newfoundland and Labrador, Prince Edward Island, and Southeastern Ontario. Kingston, Ontario: NEDSAC, Queen's University.

Özerk, K. (2016). The issue of prevalence of autism/ASD. International Electronic Journal of Elementary Education, 9(2), 263-306.

Özerk, K. \& Cardinal, D. (2018 in press). Prevalence of Autism/ASD among preschool and school-age children in Norway.

Parner, E. T., Schendel, D. E., \& Thorsen, P. (2008). Autism prevalence trends over time in Denmark: Changes in prevalence and age at diagnosis. Archives of Pediatrics and Adolescent Medicine, 162(12), 1150-1156.

Roelfsema, M. T., Hoekstra, R. A., Allison, C., Wheelwright, S., Brayne, C., Matthews, F. E., \& Baron Cohen, S. (2012). Are autism spectrum conditions more prevalent in an information-technology region? A school-based study of three regions in the Netherlands. Journal of Autism and Developmental Disorders, 42(5), 734-739.

Saemundsen, E., Magnússon, P., Georgsdóttir, I., Egilsson, E. \& Rafnsson, V. (2013). Prevalence of autism spectrum disorders in an Icelandic birth cohort. BMJ Open 2013;3:e002748. doi:10.1136/bmjopen-2013-002748

Stoltenberg, C., Schjølberg, S., Bresnahan, M., Hornig, M., Hirtz, D., Dahl, C., . . . Lipkin, W. I. (2010). The autism birth cohort: A paradigm for gene-environment-timing research. Molecular Psychiatry, 15, 676-680.

Surén, P., Bakken, I. J., Aase, H., Chin, R., Gunnes, N., Lie, K. K., ... Stoltenberg, C. (2012). Autism spectrum disorder, ADHD, epilepsy, and cerebral palsy in Norwegian children. Pediatrics, 130, 152-158.
Surén, P., Bakken, I.J., Lie, K.K., Schjølberg, S., Aase, H., Reichborn-Kjennerud, T., Magnus, P., Øyen, A-S., Kveim Svendsen, B., Aaberg, K.M., Andersen, L.G. \& Stoltenberg, C. (2013). Differences across counties in the registered prevalence of autism, ADHD, epilepsy and cerebral palsy in Norway. Tidsskrift for Norrsk Legeforening 133, 1929 - 1934.

Tebruegge, M., Nandini, V., \& Ritchie, J. (2004). Does routine child health surveillance contribute to the early detection of children with pervasive developmental disorders? - An epidemiological study in Kent, U.K. BMC Pediatrics, 4, 4. http://doi.org/10.1186/14712431-4-4

WHO (1994). International Statistical Classification of Diseases and Related Health Problems10th Revision (ICD-10). Geneva, World Health Organization.

WHO (2018). International Statistical Classification of Diseases and Related Health Problems11th Revision (ICD-11). Geneva, World Health Organization.

Williams, J. G., Higgins, J. P. T. \& Brayne, C. E. G. (2006). Systematic review of prevalence studies of autism spectrum disorders. Archives of Disease in Childhood. 91(1), 8-15. Published online 2005 Apr 29. DOI: $10.1136 /$ adc.2004.062083

Williams, K., MacDermott, S., Ridley, G., Glasson, E. J. \& Wray, J. A. (2008). The prevalence of autism in Australia. Can it be established from existing data? Journal of Paediatrics and Child Health 44, 504-510.

Wing, L. \& Potter, D. (2002). The epidemiology of autistic spectrum disorders: is the prevalence rising? Mental Retardation and Developmental Disabilities Research Reviews, 8, 151-161.

Wong, C., Odom, S. L., Hume, K. A., Cox, A. W., Fettig, A., Kucharczyk, S., . . . Schultz, T. R. (2015). Evidence-based practices for children, youth, and young adults with autism spectrum disorder: A comprehensive review. Journal of Autism and Developmental Disorders, 45, 1951-1966.

Zablotsky, B., Black, L. I., Maenner, M. J., Schieve, L. A., \& Blumberg, S. J. (2015). Estimated prevalence of autism and other developmental disabilities following questionnaire changes in the 2014 National Health Interview Survey (National Health Statistics Reports No. 87. Hyattsville, MD: U.S. Department of Health and Human Services, Centers for Disease Control and Prevention, National Center for Health Statistics. 